\title{
A Vasta Área de Atuação das Técnicas Intervencionistas Percutâneas
}

\author{
Áurea J. Chaves
}

$\mathbf{N}$ este fascículo da Revista Brasileira de Cardiologia Invasiva (RBCI), editoriais instigantes comentam tratamentos inovadores que abrangem vasta área de atuação das técnicas intervencionistas percutâneas, compreendendo desde a recanalização precoce no acidente vascular cerebral isquêmico agudo até a terapia celular nas cardiopatias, passando pelo tratamento farmacológico adjunto à angioplastia primária e pelo fechamento de defeitos septais múltiplos com mais de uma prótese.

O editorial de autoria dos neurologistas Cláudia J. Chaves e Louis R. Caplan, da Tufts University School of Medicine e da Harvard Medical School, respectivamente, em Boston, Estados Unidos, comenta as diferentes estratégias de tratamento do acidente vascular cerebral isquêmico agudo com a utilização de agentes fibrinolíticos e/ou trombólise mecânica, que visam a restabelecer rapidamente o fluxo sanguíneo cerebral, minimizar o dano tecidual e reduzir seqüelas.

O grupo liderado pelo dr. Emerson C. Perin, do Texas Heart Institute, em Houston, Estados Unidos, atualiza conceitos e perspectivas da terapia celular, fechando o ciclo de cinco revisões excepcionais, que avaliaram esse novo tratamento no infarto agudo do miocárdio, na cardiomiopatia isquêmica e na cardiomiopatia dilatada, publicados consecutivamente nos últimos fascículos da $\mathbf{R B C I}$.

O dr. Luiz Alberto Mattos, do Instituto Dante Pazzanese de Cardiologia, de São Paulo, discute a questão, ainda não resolvida, do uso rotineiro dos inibidores da glicoproteína Ilb/IIla adjuntos à angioplastia no infarto agudo do miocárdio, utilizando como recurso didático, e de forma muito criativa, algumas das citações mais conhecidas de "Hamlet", do dramaturgo e poeta inglês William Shakespeare.

Ainda neste fascículo, o dr. Carlos A. C. Pedra, também do Instituto Dante Pazzanese de Cardiologia, faz uma revisão completa dos defeitos do septo atrial múltiplos e das possibilidades de tratamento percutâneo. O título desse editorial, inspirado em conhecido ditado popular, certamente provocará ainda mais a curiosidade dos leitores.

O ano de 2008 começou com notícia muito animadora: a RBCI foi indexada no SCOPUS, o maior banco de dados científicos da atualidade, estabelecido em 2002 e patrocinado pelo grupo Elsevier. Permite o acesso eletrônico a citações e resumos de artigos científicos e oferece links para os textos completos de mais de 15 mil periódicos. Proporciona, também, instrumentos para localizar e analisar temas relevantes, fazer a procura de autores e rastrear a influência dos resultados de determinada publicação. É a ferramenta de pesquisa oferecida aos revisores de artigos de uma série de periódicos de prestígio. A inserção no SCOPUS dará maior visibilidade internacional à $\mathbf{R B C I}$, ainda restrita à esfera latino-americana, e é mais uma etapa vencida na busca do upgrade científico de nossa revista.

A partir desta edição, a composição dos artigos trará uma mudança, privilegiando ainda mais os artigos originais, que terão sua quantidade aumentada, passando a 12 artigos por edição ou $75 \%$ do total publicado, cumprindo as solicitações para a inclusão da $\mathbf{R B C I}$ na Scientific Electronic Library Online (SciELO), nossa próxima meta para a indexação.

Ajudarão a perseguir essa meta três jovens coeditores, recém-chegados de serviços de referência em Cardiologia Intervencionista no exterior, a quem damos as boas-vindas! O dr. Cristiano Cardoso, proveniente do Texas Heart Institute, de Houston, Estados Unidos, e os drs. Eduardo Missel e José Ribamar Costa, egressos da Cardiovascular Research Foundation, de Nova York, Estados Unidos, somarão seus esforços aos do dr. Carlos Pedra, desta editora e do dr. Rogério Sarmento-Leite na gratificante tarefa de conduzir a Revista. Agradecemos a contribuição inestimável do co-editor, dr. Marco Wainstein, requisitado para integrar a Comissão Científica da Sociedade Brasileira de Hemodinâmica e Cardiologia Intervencionista.

Finalizando, informamos aos caros leitores que seguimos quebrando recordes de acesso eletrônico aos artigos da $\mathbf{R B C I}$, contabilizando nos últimos 30 dias mais de sete mil consultas.

Muito obrigada por sua participação!

Áurea J. Chaves Editora 